\title{
The Strategic Decision-Making as a Complex Adaptive System: A Conceptual Scientific Model
}

\author{
Dewey Wollmann and Maria Teresinha Arns Steiner \\ Industrial and Systems Engineering Graduate Program, Polytechnic School, Pontifícia Universidade Católica do Paraná, \\ Curitiba, PR, Brazil \\ Correspondence should be addressed to Dewey Wollmann; dewey.wollmann@pucpr.br
}

Received 29 June 2016; Revised 26 August 2016; Accepted 28 August 2016; Published 9 January 2017

Academic Editor: Dimitri Volchenkov

Copyright ( 2017 D. Wollmann and M. T. A. Steiner. This is an open access article distributed under the Creative Commons Attribution License, which permits unrestricted use, distribution, and reproduction in any medium, provided the original work is properly cited.

\begin{abstract}
A company in a competitive environment that wishes to be a benchmark in the business world needs a management model that enables the development of systemic thinking on the part of its executives. In addition to systemic thinking, it is also necessary that executives (i) are aware that the decision-making processes should be shared, (ii) have bounded rationality, and (iii) exert political influence according to their preferences. In this context, the aim of this paper is to describe a conceptual scientific model for strategic decision-making from rules originating from Complex Adaptive Systems and the following mathematical techniques: Analytic Network Process and Linear Programming. This applied and quantitative study is a theoretical essay developed from an integrative review of the aforementioned concepts and techniques, resulting in the proposition of a scientific and conceptual mathematical model that can be applied to a wide variety of business environments. The results obtained from a hypothetical example (Strategic Operation Management Decision) show that the model is able to rank a set of strategic decisions in the environment of most companies and generate information to minimize the negative effects of shared decisions.
\end{abstract}

\section{Introduction}

Any company operating in a competitive environment that desires to become a benchmark in the business world needs a managerial model that enables the development of systemic thinking on the part of its executives.

The current Information and Knowledge Age coexists with emerging models, such as the models based on complexity theories. Of these models, systems thinking and nonlinearity stand out. Systems thinking can be understood as a philosophy or a way of producing, interpreting, and using knowledge. It is a method for solving problems and organizing complex sets of concepts and fragmented views. It enables the integration of concepts and specific theories with a view to interpreting and seeking solutions to complex problems. This has led to changing paradigms in decisionmaking processes $[1,2]$.

This process is especially important in companies when it comes to determining strategies to achieve long-term goals [3-7]. In environments of uncertainty, it is increasingly difficult to make strategic decisions because (i) there are no precedents to follow; (ii) most of the time decisions are not structured; (iii) they compromise significant resources; (iv) they require a high level of commitment; and (v) they affect operational aspects $[3,5,8]$.

To Mintzberg and Quinn [9], Bin and Castor [3], Engle [10], and Diga [11], companies are not only instruments for the production of goods and services, but also political systems that seek to increase their own power. These political systems can be more or less democratic, depending on the profile of the agents involved in making decisions. In companies with democratic systems, decision-making is based on a permanent drive for representation in discussions. To Barros [12], Nooraie [5], and Diga [11], decisions-making is made from consolidations of consensus levels regarding social preferences.

According to Bin and Castor [3], Nooraie [5], Alam [13], Ahmed et al. [7], and Diga [11], the decision-making agents are exposed to a set of internal and external pressures. In the daily life of companies, decision-making agents need 
to manage conflicting perceptions and interests, eliminate antagonistic positions and disputes for resources and information, transforming organizational goals into collective goals, and seek to satisfy the stakeholders.

Bin and Castor [3], Barros [12], Stephenson [14], Engle [10], Alam [13], and Diga [11] highlight that companies are political systems in which the agents involved in strategic decisions-making have partly conflicting goals and limited cognitive capacity. Therefore, strategic decision-making is best described by a combination of paradigms of limited rationality and organizational politics. This is a limited rationale because the decision-making agents are cognitively limited and develop the rational decision-making process repetitively. It is political in the sense that the strategic decision agents are also involved in political activities, disputing power to define decisions.

According to Roberto [15], Bin and Castor [3], Citroen [16], Barros [12], Stephenson [14], and Ahmed et al. [7], an effective decision-making process requires an adequate environment to harmonize the subjectivities, uncertainty, and inaccuracy that are always present in decision-making agents. Power relations, when well managed, can result in the prevention and resolution of conflicts and ensure that organizational balance and growth are maintained. Strategic choice is something that should be constructed incrementally by individuals with different values and goals. A conceptual scientific model can facilitate this process, making it clearer and more objective.

According to Carlile and Christensen [17], it is necessary to think of "theory" as a set of knowledge that researchers develop cumulatively. This means reflecting on how theories are constructed: (i) first of all by observing reality, proposing a model to explain it, and (ii) secondly by proposing a model that will be tested in practice.

In the conclusion of their study, Fleury and Borgatti Neto [18] state that (i) the construction of virtual models to study complex systems can lead to an accelerated coevolution in all areas of knowledge and (ii) new organizational models will be developed and old ideas of organizational theories could be boosted by learning from virtual dynamics and thus new theories will emerge.

In this context, a conceptual scientific model is proposed for strategic decision process (under the influence of limited rationality and organizational policy), resulting from the integration of the theories of administration (strategic decisionmaking) and complexity (Complex Adaptive System) and mathematical techniques: Analytic Network Process (ANP) and Linear Programming (LP). These theories and techniques are already well known but used in isolation. Here they will be used jointly to compose the conceptual scientific model.

Therefore, the present study is important and unprecedented as it proposed the creation of a conceptual scientific model for strategic decision processes under the influence of limited rationality and organizational policy and can be applied in any business environment.

This study is organized in five sections. In Section 2, there is a summary of the theoretical background that supports the study. Section 3 describes the conceptual scientific model. An evaluation of the model is presented in Section 4 using a hypothetical example. Finally, Section 5 presents the conclusions and some suggestions for future works.

\section{Theoretical Background}

In this section, the concepts and techniques involved in the proposed conceptual scientific model are presented and discussed. These techniques are the Complex Adaptive System (CAS), Analytic Network Process (ANP), and Linear Programming (LP). As the last one (LP) is very known by the scientific community, it is not presented at this section but in the next.

2.1. Complex Adaptive Systems. According to Bar-Yam [19] and Stacey [20], systems are complex by nature and adaptive in that they have coevolutionary characteristics, that is, when they depend on the system learning. Their intrinsic dynamic nature of complex systems requires them to have capacity to adapt, and this is fundamental for their survival.

Complex Adaptive Systems (CAS) are systems made up of components (agents) that interact with one another according to a set of rules. The evolution of the system is the result of interactions between agents, where each of them acts in response to the behavior of the other agents in the system, which ensure it has its own dynamic. According to Stacey [20], the behavior of each agent influences and is influenced by the behavior of the system as a whole. CAS learn and evolve, using an adaptive approach that is fundamental to their survival, processing information, and constructing schema, based on what they have experienced.

According to Bar-Yam [19] and Qudrat-ullah et al. [21], CAS can be represented by mathematical models with logic similar to dynamic and self-organizing systems. The agents of a CAS have rules of interaction. A generic model of a CAS, prepared by the NECSI (New England Complex Systems Institute), is shown in Figure 1. The model considers that external influences (variables from the external environment) are detected by internal agents (Environmental Surveillance System) of the CAS that act as sensors open to the external environment. When the CAS perceives these stimuli, it developed internal processes based on its system of rules, seeking reorganization. Other internal agents (system that reacts to external influences) act on the external environment. A feedback circuit enables continuous learning and adaptation of the CAS to the resulting process of external change and internal reorganizations.

2.2. Analytic Network Process. According to Wollmann et al. [22] and Franek and Kashi [23], multiattribute decisionmaking methods can be classified in accordance with the denominations of the French school and the American school. The methods of the French school propose more flexible models that do not necessarily assume a comparison of the alternatives and do not impose a hierarchical criteria structure on the decision agent. The methods of the American school are associated with the Multi-Attribute Utility Theory, which is based on the hypothesis that in any decisionmaking problem there is a real value function on the set 


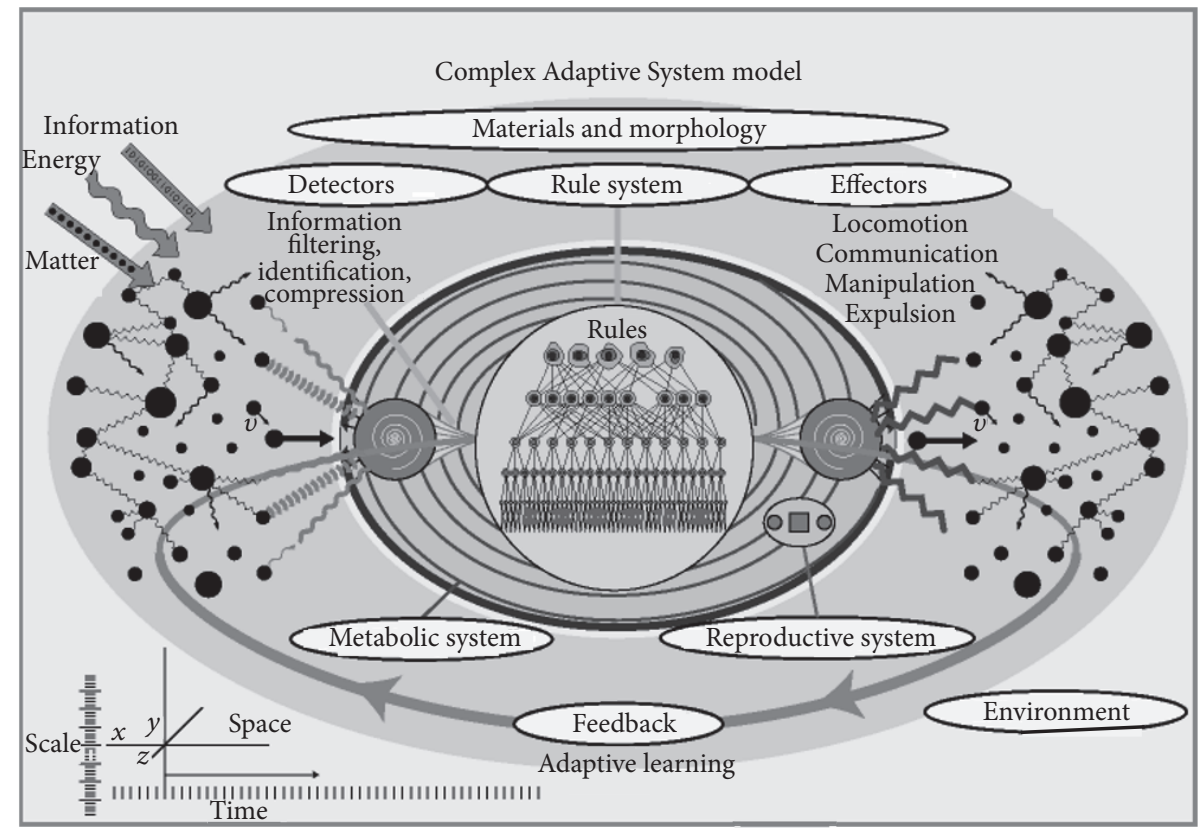

FIGURE 1: Generic model of a CAS. Source: http://www.necsi.edu/projects/mclemens/casmodel.gif.

of alternatives, and this function adds the attributes and should be defined by the decision agent. Thus, the theory assumes that the decision agent is capable of identifying various discrete alternatives for evaluation and is capable of structuring the criteria on which the alternatives will be evaluated hierarchically.

One of the best known and perhaps the most widely used methods and most mentioned in the literature belongs to the American school. This is the Analytic Hierarchy Process (AHP) [24-28].

This method is based on the concept of hierarchical analysis, which establishes structuring of criteria at hierarchical levels to create a homogeneity between criteria of the same level; that is, the criteria must have the same level of importance, thereby facilitating their understanding and evaluation. The AHP begins with the decomposition of the problem into a hierarchy of attributes that are not easily analyzed and compared independently. From the moment when this logical hierarchy is constructed, the following stage of the AHP is to evaluate the alternatives systematically by pairwise comparison from the viewpoint of each criterion or attribute. For this comparison, concrete data on the alternatives or human judgement can be used as a form of information [22, 24-26, 29, 30].

Two elements can be compared using the AHP in different ways. However, the relative importance scale of two alternatives, proposed by Saaty [29], is the most widely used. The use of this scale to evaluate criteria and/or attributes generates a consolidated matrix with numerical values. The main procedure is used to evaluate pairs of alternatives from the viewpoint of each of the criteria and/or attributes $[22,24-26,29,30]$.

The matrices on the judgement of preferences are not always consistent; that is, they cannot be used for the ranking of preferences. This occurs for two reasons: (i) difficulty in adjusting the Saaty scale to the comparisons pairwise and (ii) the limited rationality of the judges.

To ensure the consistency of the preference matrices, a method developed by Davoodi [31] and Wollmann et al. [22] was adopted, which suggests that the preference matrix is unfolded in " $n$ " provisory matrices, but each one has as a reference one of the columns of the original matrix, and the other elements can be determined proportionally. From these " $n$ " matrices, a matrix (preference matrix) will be obtained, and it will always be consistent. It will then be possible to continue the procedure.

These evaluations, with their respective weight attributions, can be conducted by $K$ judges. With the evaluation matrices of all the $K$ judges, it is necessary to establish a single set of matrices (attributes and alternatives per attribute) that represent the whole evaluation process. The geometric mean of the values should be used as, in this way, the characteristics of the weights and their reciprocals will be maintained [29, 30, 32].

The ANP, in turn, is a generalization of the AHP, as it organizes the decision model into a network of components of alternatives, criteria, objectives, and other factors that influence the properties of each of these elements. This enables greater flexibility in defining the decision-making process, as it considers interdependencies and interrelations between the decision components and the different elements (factors) that represent the scenario in question [24, 27, 30, 33-36].

In the ANP, the network elements are organized into homogeneous clusters (Figure 2). Paired comparisons are then made of the elements in relation to an element higher up in the relationship network. The comparisons are made by using Saaty's fundamental scale. These paired comparisons, 


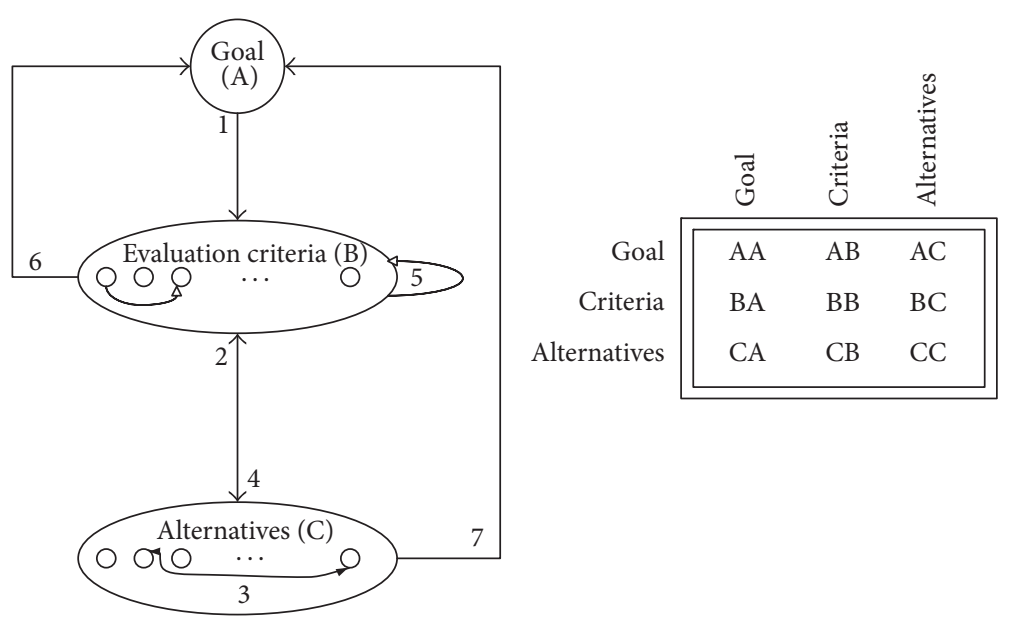

FIGURE 2: ANP structure and its corresponding unweighted supermatrix. Source: [37].

according to Ocampo and Clark [37], are organized into an unweighted supermatrix.

The values of the initial supermatrix blocks (e.g., "AB") are the estimated priorities, indicating the relative strength of the dominant position of one element over another in relation to a common element, from which the arc emanates. The eigenvector method (also used in the AHP) is the method used to quantify the relative dominance of the elements of paired comparison matrices. The unweighted supermatrix is then normalized; that is, the sum of all the columns must be equal to " 1 ".

The solution to the problem through the ANP model is obtained by calculating the "matrix limit." This is the normalized supermatrix elevated to the power $(k+1)$, where $k$ is an arbitrary number. This procedure makes the values of the diverse elements in the matrix converge, thus identifying the degree of influence between these elements. The values of this "matrix limit" are the priorities of the desired elements regarding the objective.

Due to the characteristics of this study, mainly regarding the decision agents, the ANP was the chosen technique. Thus, an attempt is made to minimize the problems identified by Bond et al. [38] regarding the decision agents defining the criteria and ranking them in their decision processes. This is because, as explained above, the ANP structures the criteria and alternatives in clusters and establishes connections and interdependence between them, facilitating the understanding of the decision agents.

\section{Conceptual Scientific Model}

The conceptual scientific model proposed here emerged from the observation of the relationships between the concepts of the complexity and systems optimization techniques presented in Section 2.

To Richardson [39], Meyer Jr. et al. [40], Wollmann and Steiner [1], and Wollmann et al. [2] companies have a behavior dynamic because interactions between their parts (functional areas such as marketing, production, human resources, and finance) promote continuous changes. At the same time, the parts exchange energy (which materializes in the form of information and resources) with the environment (political, social, economic, technological, and competitive) in which the company is embedded. This promotes deliberate internal adaptations of all its parts. In this exchange of energy, modifications can also occur in parts of this environment, thus showing that companies are dynamic and dissipative systems.

According to Stacey [20], a CAS is made up of agents who interact in a nonlinear fashion. To Morin [41], this interaction has a holographic characteristic; that is, the interaction between the parts is continuously recreating the whole at the same time as the whole affects each of the parts. The interaction and learning of agents occurs individually through a set of processes: (i) discovery; (ii) choice; and (iii) action.

The agents or parts play a central role in the functions of both CAS and companies. The agents are responsible for interactions and the decision process [1, 2, 20, 39]. They determine and articulate the direction in which the system or company will develop. They set priorities from which they make their own decisions in a dynamic between conformity and individualism. They evaluate how other agents respond to their actions. Favorable responses to their actions are repeated while unfavorable responses generate a change in their behavior. It is the responsibility of the agents to make the system legitimate through formal and informal interactions, stimulating and developing feedback networks. Feedback networks, in turn, encourage learning and creativity of agents and lead to self-organization and the evolution of the system.

As mentioned above, the agents set priorities and interact with other agents to reach a consensus. This phenomenon can be measured mathematically using two techniques: (i) the ANP, which defines the interdependence between the business dimensions and strategic decisions (in accordance with the desires and priorities of the agents), and (ii) LP, which optimizes the priorities of the different strategic decisions. 
TABLE 1: Relationships between CAS and the conceptual scientific model.

\begin{tabular}{ll}
\hline Complex Adaptive System & Conceptual scientific model \\
\hline $\begin{array}{l}\text { External environment } \\
\text { variables }\end{array}$ & $\begin{array}{l}\text { Partners + shareholders } \\
\text { Economy } \\
\text { Market (consumers + competitors) } \\
\text { Technology } \\
\text { Society + trade union }\end{array}$ \\
\hline $\begin{array}{l}\text { Environmental Surveillance } \\
\text { System }\end{array}$ & Decision agents \\
\hline & $\begin{array}{l}\text { ANP } \\
\text { Davoodi method (consistency of the preference matrices) } \\
\text { Aczél and Saaty method (" } n \text { " decision agents) }\end{array}$ \\
\hline Reaction system & RP Ranked strategic decisions \\
\hline Set of actions & Strategic decision implementation \\
\hline & $\begin{array}{l}\text { Comparison of individual decisions with the results of corrections related to the consistency of the } \\
\text { preference matrices } \\
\text { Comparison of individual decisions with the results of decisions to decision-makers group } \\
\text { Edaptive learning }\end{array}$ \\
& Evaluation of hierarchical strategic decisions \\
\hline
\end{tabular}

Source: the authors.

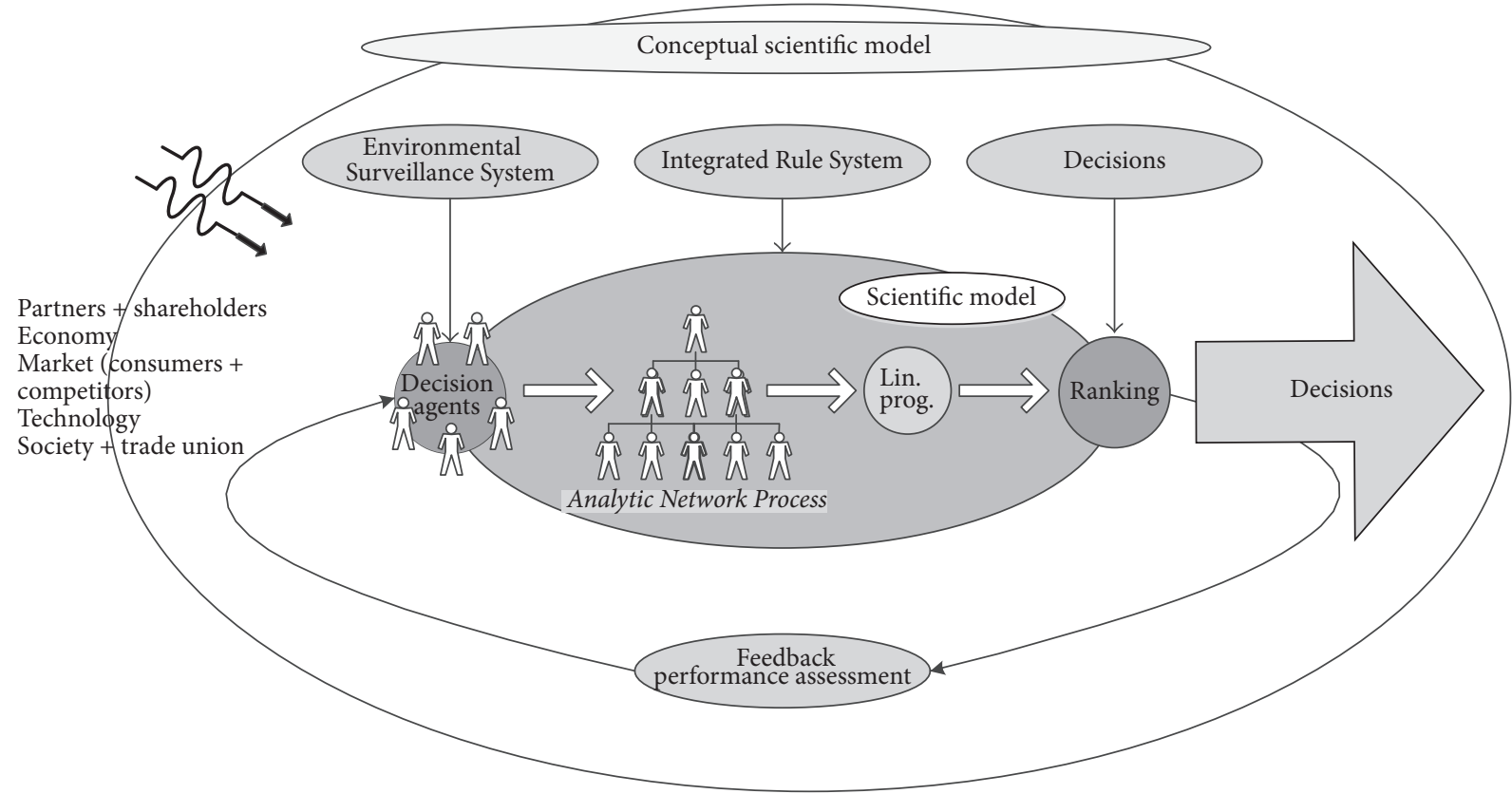

FIgURE 3: Conceptual scientific model. Source: the authors.

Thus, the model of a CAS shown in Figure 1 can be "translated" to the business environment (Table 1). Table 1 shows the relationships between the elements of a CAS and the proposed conceptual scientific model, with its graphic representation showing the integration between the theories and techniques used shown in Figure 3.

The largest ellipse in Figure 3, which represents the company, is influenced by the external environment through the company partners, the economy, consumers, competitors, technology, and the workers. These external influences, represented by variables, are detected and analyzed by an
Environmental Surveillance System composed of the decision agents.

The Environmental Surveillance System, after analyzing the influences from the external environment, generates information (strategic decisions) with certain tendencies resulting from the managerial profiles: limited rationality and power in the organization of each decision agent, for the Integrated Rule System.

The Integrated Rule System, in turn, is made up of two subsystems: (i) the ranking (structured based on the ANP) and (ii) optimization (LP model). 


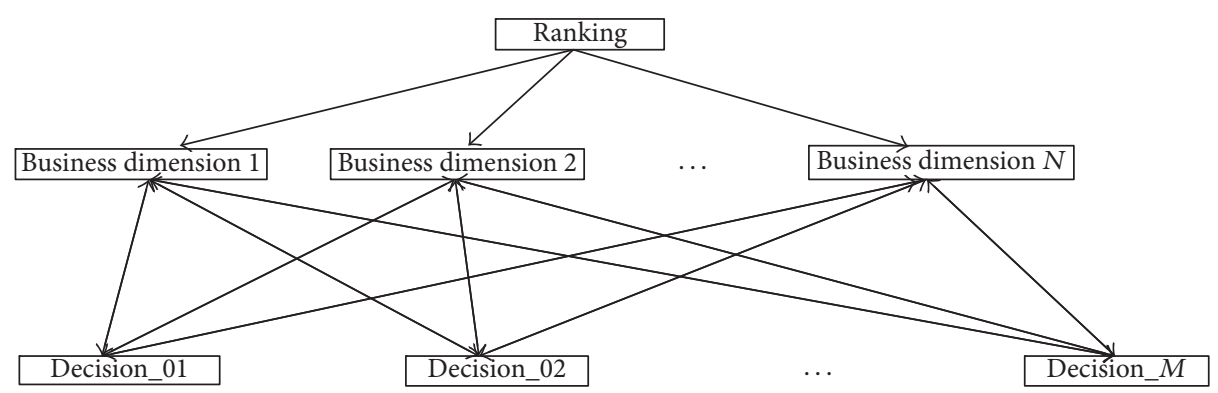

FIGURE 4: Ranking of preferences. Source: the authors.

The ranking subsystem is structured as shown inFigure 4, which shows (i) a main hierarchy: ranking, business dimensions, and strategic decisions and (ii) the relationships of interdependence between the business dimensions and strategic decisions. Each of these decision agents evaluates the relative importance of the influences between the diverse elements in the network. The ANP model, in turn, determines the hierarchy of preferences that corresponds to the harmonized "interests" of all the decision agents.

The result of the ranking subsystem is "made available" to the optimization subsystem. This subsystem is responsible for the optimization of the ranking of the strategic decisions. For this purpose, the following binary integer linear programming model can be used:

$$
\begin{aligned}
\max & Z=\sum_{i} p_{i} \cdot x_{i} \\
\text { subject to: } & \sum_{i} a_{i} \cdot x_{i} \leq O \\
& x_{i}=\text { binary, }
\end{aligned}
$$

where $p_{i}$ is the preference index for the strategic decision $i$, obtained by the ANP; $a_{i}$ is the cost of implementing the strategic decision $i$; and $O$ is the company budget. Thus, (1) maximizes the preferences in relation to the strategic decisions $i$ of the company; the restriction (2) ensures that the costs $a_{i}$ of implementing the strategic decisions $i$ are not higher than the budget $O$ made available by the company; and in (3) $x_{i}=$ " 1 " if the strategic decision $i$ is selected and " 0 " if it is not.

The Integrated Rule System generates the first ranking of strategic decisions, considering

(i) the limited rationality of the deciders (corrections of the preference matrix of each agent using the Davoodi method),

(ii) the power of the decision agents in the company (corrections of the preference matrix of each agent using the Aczél and Saaty method),

(iii) the democratic decision environment (Aczél and Saaty method),

(iv) the impact of the business dimensions (market, operation, people, and finances) on the strategic decisions (ANP), (v) the impact of the strategic decisions on the business dimensions (ANP),

(vi) the cost of implementing the strategic decisions (PL),

(vii) the company budget for the implementation of strategic decisions (PL).

Finally, the Performance Evaluation System indicates adjustments to be implemented in the Environmental Surveillance System and the Integrated Rule System. The decision agents analyze and share the information generated in the systems. With this sharing, it is possible for the agents to "learn" (i) from the corrections of judgement of their preferences [31] and (ii) from the equilibrium between individual and company objectives (ANP). This learning explains the learning characteristics of the proposed model, as occurs in CAS.

\section{Example of Application: Strategic Operations Management Decisions}

To provide an example of the use of the proposed model, a hypothetical industrial company with five decision agents was considered. They need to rank five operational strategic decisions: (i) internalization of new technologies (NT), (ii) new product development (NP), (iii) a planning and control system (PCS), (iv) capacity adjustment (CA), and (v) organization and people (O_HR), with their respective implementation costs $(30 \%, 20 \%, 25 \%, 15 \%$, and $35 \%$ of the budget, resp.) and the known budget (100\%), in accordance with the following competitiveness factors: (i) price, (ii) quality, (iii) delivery, and (iv) innovation.

The ANP structure for this situation is shown in Figure 4 (with $N=4$ and $M=5$ ). Table 2 is the unweighted supermatrix corresponding to the ANP network structure of the applied example.

The values $x_{i}(i=1, \ldots, 4)$ correspond to the preferences of the decision agents in relation to the business dimensions. The values $y_{i j}(i=1, \ldots, 4$ and $j=1, \ldots, 5)$ correspond to the preferences of the decision agents in relation to the importance of the strategic decisions for each of the business dimensions. The values $w_{i j}(i=1, \ldots, 4$ and $j=1, \ldots, 5)$, in turn, correspond to the preferences of the decision agents regarding the importance of the business dimensions for each of the strategic decisions. 
TABLE 2: Supermatrix of the applied example.

\begin{tabular}{|c|c|c|c|c|c|c|c|c|c|c|}
\hline & Ranking & Price & Quality & Delivery & Innovation & NT & NP & PCS & CA & O_HR \\
\hline Ranking & 0 & 0 & 0 & 0 & 0 & 0 & 0 & 0 & 0 & 0 \\
\hline Price & $\mathrm{x}_{1}$ & 0 & 0 & 0 & 0 & $w_{11}$ & $w_{12}$ & $\mathrm{w}_{13}$ & $\mathrm{w}_{14}$ & $w_{15}$ \\
\hline Quality & $x_{2}$ & 0 & 0 & 0 & 0 & $\mathbf{w}_{21}$ & $\mathbf{w}_{22}$ & $\mathbf{w}_{23}$ & $\mathbf{w}_{24}$ & $\mathbf{w}_{25}$ \\
\hline Delivery & $x_{3}$ & 0 & 0 & 0 & 0 & $w_{31}$ & $w_{32}$ & $\mathbf{w}_{33}$ & $\mathrm{w}_{34}$ & $\mathbf{w}_{35}$ \\
\hline Innovation & $\mathbf{x}_{4}$ & 0 & 0 & 0 & 0 & $w_{41}$ & $w_{42}$ & $w_{43}$ & $\mathrm{w}_{44}$ & $w_{45}$ \\
\hline NT & 0 & $y_{11}$ & $y_{21}$ & $\mathrm{y}_{31}$ & $y_{41}$ & 0 & 0 & 0 & 0 & 0 \\
\hline NP & 0 & $y_{12}$ & $y_{22}$ & $y_{32}$ & $y_{42}$ & 0 & 0 & 0 & 0 & 0 \\
\hline PCS & 0 & $y_{13}$ & $y_{23}$ & $y_{33}$ & $y_{43}$ & 0 & 0 & 0 & 0 & 0 \\
\hline CA & 0 & $y_{14}$ & $y_{24}$ & $y_{34}$ & $y_{44}$ & 0 & 0 & 0 & 0 & 0 \\
\hline O_HR & 0 & $\mathrm{y}_{15}$ & $y_{25}$ & $y_{35}$ & $y_{45}$ & 0 & 0 & 0 & 0 & 0 \\
\hline
\end{tabular}

Source: the authors.

TABLE 3: Average index of consistency of the preference matrix.

\begin{tabular}{lc}
\hline Decision agents & $\begin{array}{c}\text { Average index of consistency of } \\
\text { the preference matrix }\end{array}$ \\
\hline Agent 1 & 0.15 \\
Agent 2 & 0.26 \\
Agent 3 & 0.29 \\
Agent 4 & 0.24 \\
Agent 5 & 0.21 \\
\hline
\end{tabular}

Source: the authors.

The values of $x_{i}, y_{i j}$, and $w_{i j}$ are determined from the preferences, defined by each of the decision agents and registered on a paired comparison spreadsheet (AHP technique).

The preference matrix of each of the decision agents is inconsistent due to the bounded rationality phenomenon as can be seen in Table 3. This table shows the average indices of consistency of preference matrix of decision agents.

With these results, the conceptual scientific model proposed establishes two actions: (i) determine the consistent preference matrices, by means of the Davoodi technique [31], and (ii) inform every decision agent of their inconsistency indices and the results of the matrices modified by the previous action. The second action model is part of the Performance Evaluation System and generates the learning opportunity of the decision agents.

The consistent preference matrices, of each decision agent, resulting from the first action are arranged in unweighted supermatrices and then normalized (ANP). The normalized supermatrices of each of the decision agents are represented in Tables 4, 5, 6, 7, and 8. These supermatrices correspond to the preferences of the decision agents, considering the minimization of its bounded rationality.

In the next step, a consolidation of the preference matrices of the decision agents is made from the scientific concept model. The technique proposed by Aczél and Saaty [32] is used. The elements of the consistent and consolidated matrices are then organized into the unweighted supermatrix, which in turn is normalized. The normalized supermatrix, which is representative of this hypothetical example, is shown in Table 9.

The columns of the normalized supermatrix (Table 9) correspond to the preferences of the decision agents, considering the minimization of limited rationality and the harmonization of individual preferences.

Next stage of conceptual scientific model is to determine the limit of the matrices corresponding to each decision agent and the consolidation of all agents (Tables 4-9). For this, each super-matrix is raised to a significantly large power in order to have the converged values, that is, stabilized. Elevating the normalized supermatrix to the power " 10 " generates the matrix limit. The values of the columns converge to the solution of the ANP model. The values of the elements of the matrix limit are shown in Tables 10, 11, 12, 13, 14, and 15. The values in bold font correspond to the ranking column and are the preference values of the strategic decisions of this example application.

The results of the matrices limit, which represents the preferences of the decision agents, are consolidated in Table 16.

With these results, the conceptual scientific model proposed establishes two more actions: (i) determining the ranking of operations strategies to be implemented through the PL and (ii) informing each decision agent of their global and individual preferences. The second action of the model is also part of the Performance Evaluation System and generates the learning opportunity of the decision agents.

Now the resultant preferences from the consolidation of all the decision agents become part of the binary integer linear programming model so that they can be optimized. The resulting model is described from (4), where DE_01 is the strategic decision related to new technologies $($ DE_02 = etc.):

$\max 0.09 \times$ DE_01 $+0.14 \times$ DE_02 $+0.28 \times$ DE_03 $+0.16 \times$ DE_0 $4+0.32 \times$ DE_05

subject to: $\quad 0.30 \times \mathrm{DE} \_01+0.20 \times \mathrm{DE} \_02+0.25 \times \mathrm{DE} \_03+0.15 \times \mathrm{DE} \_04+0.35 \times \mathrm{DE} \_05 \leq 1.00$

$\mathrm{DE} i=$ " 1 ", if the decision will be implemented, and "0", if it is not. 
TABLE 4: Normalized supermatrix of decision agent 1.

\begin{tabular}{lcccccccccc}
\hline & Ranking & Price & Quality & Delivery & Innovation & NT & NP & PCS & CA & O_HR \\
\hline Ranking & 0.00 & 0.00 & 0.00 & 0.00 & 0.00 & 0.00 & 0.00 & 0.00 & 0.00 & 0.00 \\
Price & $\mathbf{0 . 3 3}$ & 0.00 & 0.00 & 0.00 & 0.00 & $\mathbf{0 . 5 8}$ & $\mathbf{0 . 2 9}$ & $\mathbf{0 . 1 0}$ & $\mathbf{0 . 0 7}$ & $\mathbf{0 . 0 9}$ \\
Quality & $\mathbf{0 . 2 0}$ & 0.00 & 0.00 & 0.00 & 0.00 & $\mathbf{0 . 2 3}$ & $\mathbf{0 . 5 5}$ & $\mathbf{0 . 6 0}$ & $\mathbf{0 . 1 1}$ & $\mathbf{0 . 2 7}$ \\
Delivery & $\mathbf{0 . 0 4}$ & 0.00 & 0.00 & 0.00 & 0.00 & $\mathbf{0 . 1 3}$ & $\mathbf{0 . 0 5}$ & $\mathbf{0 . 2 5}$ & $\mathbf{0 . 2 3}$ & $\mathbf{0 . 5 9}$ \\
Innovation & $\mathbf{0 . 4 3}$ & 0.00 & 0.00 & 0.00 & 0.00 & $\mathbf{0 . 0 6}$ & $\mathbf{0 . 1 1}$ & $\mathbf{0 . 0 5}$ & $\mathbf{0 . 5 9}$ & $\mathbf{0 . 0 6}$ \\
NT & 0.00 & $\mathbf{0 . 5 1}$ & $\mathbf{0 . 0 4}$ & $\mathbf{0 . 0 5}$ & $\mathbf{0 . 1 5}$ & 0.00 & 0.00 & 0.00 & 0.00 & 0.00 \\
NP & 0.00 & $\mathbf{0 . 2 3}$ & $\mathbf{0 . 0 8}$ & $\mathbf{0 . 0 8}$ & $\mathbf{0 . 4 7}$ & 0.00 & 0.00 & 0.00 & 0.00 & 0.00 \\
PCS & 0.00 & $\mathbf{0 . 1 6}$ & $\mathbf{0 . 2 4}$ & $\mathbf{0 . 2 9}$ & $\mathbf{0 . 2 9}$ & 0.00 & 0.00 & 0.00 & 0.00 & 0.00 \\
CA & 0.00 & $\mathbf{0 . 0 7}$ & $\mathbf{0 . 1 7}$ & $\mathbf{0 . 2 6}$ & $\mathbf{0 . 0 3}$ & 0.00 & 0.00 & 0.00 & 0.00 & 0.00 \\
O_HR & 0.00 & $\mathbf{0 . 0 3}$ & $\mathbf{0 . 4 6}$ & $\mathbf{0 . 3 3}$ & $\mathbf{0 . 0 7}$ & 0.00 & 0.00 & 0.00 & 0.00 & 0.00 \\
\hline
\end{tabular}

Source: the authors.

TABle 5: Normalized supermatrix of decision agent 2.

\begin{tabular}{lcccccccccc}
\hline & Ranking & Price & Quality & Delivery & Innovation & NT & NP & PCS & CA & O_HR \\
\hline Ranking & 0.00 & 0.00 & 0.00 & 0.00 & 0.00 & 0.00 & 0.00 & 0.00 & 0.00 & 0.00 \\
Price & $\mathbf{0 . 2 6}$ & 0.00 & 0.00 & 0.00 & 0.00 & $\mathbf{0 . 0 5}$ & $\mathbf{0 . 1 4}$ & $\mathbf{0 . 0 6}$ & $\mathbf{0 . 0 7}$ & $\mathbf{0 . 0 6}$ \\
Quality & $\mathbf{0 . 1 2}$ & 0.00 & 0.00 & 0.00 & 0.00 & $\mathbf{0 . 1 1}$ & $\mathbf{0 . 6 3}$ & $\mathbf{0 . 5 2}$ & $\mathbf{0 . 1 5}$ & $\mathbf{0 . 2 5}$ \\
Delivery & $\mathbf{0 . 0 4}$ & 0.00 & 0.00 & 0.00 & 0.00 & $\mathbf{0 . 2 7}$ & $\mathbf{0 . 0 6}$ & $\mathbf{0 . 3 2}$ & $\mathbf{0 . 2 4}$ & $\mathbf{0 . 5 8}$ \\
Innovation & $\mathbf{0 . 5 7}$ & 0.00 & 0.00 & 0.00 & 0.00 & $\mathbf{0 . 5 7}$ & $\mathbf{0 . 1 8}$ & $\mathbf{0 . 1 0}$ & $\mathbf{0 . 5 4}$ & $\mathbf{0 . 1 1}$ \\
NT & 0.00 & $\mathbf{0 . 5 2}$ & $\mathbf{0 . 0 4}$ & $\mathbf{0 . 0 4}$ & $\mathbf{0 . 1 1}$ & 0.00 & 0.00 & 0.00 & 0.00 & 0.00 \\
NP & 0.00 & $\mathbf{0 . 2 3}$ & $\mathbf{0 . 0 6}$ & $\mathbf{0 . 0 7}$ & $\mathbf{0 . 3 7}$ & 0.00 & 0.00 & 0.00 & 0.00 & 0.00 \\
PCS & 0.00 & $\mathbf{0 . 1 6}$ & $\mathbf{0 . 2 2}$ & $\mathbf{0 . 2 7}$ & $\mathbf{0 . 3 8}$ & 0.00 & 0.00 & 0.00 & 0.00 & 0.00 \\
CA & 0.00 & $\mathbf{0 . 0 6}$ & $\mathbf{0 . 1 3}$ & $\mathbf{0 . 2 6}$ & $\mathbf{0 . 0 4}$ & 0.00 & 0.00 & 0.00 & 0.00 & 0.00 \\
O_HR & 0.00 & $\mathbf{0 . 0 3}$ & $\mathbf{0 . 5 5}$ & $\mathbf{0 . 3 7}$ & $\mathbf{0 . 1 1}$ & 0.00 & 0.00 & 0.00 & 0.00 & 0.00 \\
\hline
\end{tabular}

Source: the authors.

TABLE 6: Normalized supermatrix of decision agent 3.

\begin{tabular}{lcccccccccc}
\hline & Ranking & Price & Quality & Delivery & Innovation & NT & NP & PCS & CA & O_HR \\
\hline Ranking & 0.00 & 0.00 & 0.00 & 0.00 & 0.00 & 0.00 & 0.00 & 0.00 & 0.00 & 0.00 \\
Price & $\mathbf{0 . 4 0}$ & 0.00 & 0.00 & 0.00 & 0.00 & $\mathbf{0 . 3 5}$ & $\mathbf{0 . 0 8}$ & $\mathbf{0 . 0 8}$ & $\mathbf{0 . 1 7}$ & $\mathbf{0 . 0 4}$ \\
Quality & $\mathbf{0 . 1 4}$ & 0.00 & 0.00 & 0.00 & 0.00 & $\mathbf{0 . 2 2}$ & $\mathbf{0 . 6 1}$ & $\mathbf{0 . 6 0}$ & $\mathbf{0 . 2 4}$ & $\mathbf{0 . 2 4}$ \\
Delivery & $\mathbf{0 . 0 4}$ & 0.00 & 0.00 & 0.00 & 0.00 & $\mathbf{0 . 2 3}$ & $\mathbf{0 . 0 5}$ & $\mathbf{0 . 2 7}$ & $\mathbf{0 . 2 2}$ & $\mathbf{0 . 6 4}$ \\
Innovation & $\mathbf{0 . 4 2}$ & 0.00 & 0.00 & 0.00 & 0.00 & $\mathbf{0 . 2 1}$ & $\mathbf{0 . 2 7}$ & $\mathbf{0 . 0 5}$ & $\mathbf{0 . 3 7}$ & $\mathbf{0 . 0 9}$ \\
NT & 0.00 & $\mathbf{0 . 0 4}$ & $\mathbf{0 . 1 2}$ & $\mathbf{0 . 0 7}$ & $\mathbf{0 . 1 1}$ & 0.00 & 0.00 & 0.00 & 0.00 & 0.00 \\
NP & 0.00 & $\mathbf{0 . 0 6}$ & $\mathbf{0 . 1 0}$ & $\mathbf{0 . 0 9}$ & $\mathbf{0 . 2 9}$ & 0.00 & 0.00 & 0.00 & 0.00 & 0.00 \\
PCS & 0.00 & $\mathbf{0 . 1 6}$ & $\mathbf{0 . 2 4}$ & $\mathbf{0 . 3 2}$ & $\mathbf{0 . 3 9}$ & 0.00 & 0.00 & 0.00 & 0.00 & 0.00 \\
CA & 0.00 & $\mathbf{0 . 2 2}$ & $\mathbf{0 . 1 3}$ & $\mathbf{0 . 2 5}$ & $\mathbf{0 . 0 5}$ & 0.00 & 0.00 & 0.00 & 0.00 & 0.00 \\
O_HR & 0.00 & $\mathbf{0 . 5 1}$ & $\mathbf{0 . 4 1}$ & $\mathbf{0 . 2 8}$ & $\mathbf{0 . 1 6}$ & 0.00 & 0.00 & 0.00 & 0.00 & 0.00 \\
\hline
\end{tabular}

Source: the authors.

The solution of this model, which corresponds to the result of the conceptual scientific model for ranking a set of strategic decisions, taking into consideration the results in Table 5, is as follows:

(i) DE_01 = 0; that is, the decision related to "new technologies" will not be implemented;

(ii) $\mathrm{DE}_{-} 02=1$; that is, the strategic decision regarding "new products" will be implemented (third place; weight $=14 \%$; (iii) DE_03 = 1; that is, the strategic decision on "Control and Planning System" will be implemented (second place; weight $=28 \%$ );

(iv) DE_04 = 1; that is, the strategic decision on "capacity adjustment" will be implemented (fourth place; weight $=16 \%)$;

(v) DE_05 = 1; that is, the strategic decision on "organization and people" will be implemented (first place; weight $=32 \%$ ). 
TABLE 7: Normalized supermatrix of decision agent 4.

\begin{tabular}{lcccccccccc}
\hline & Ranking & Price & Quality & Delivery & Innovation & NT & NP & PCS & CA & O_HR \\
\hline Ranking & 0.00 & 0.00 & 0.00 & 0.00 & 0.00 & 0.00 & 0.00 & 0.00 & 0.00 & 0.00 \\
Price & $\mathbf{0 . 2 5}$ & 0.00 & 0.00 & 0.00 & 0.00 & $\mathbf{0 . 2 5}$ & $\mathbf{0 . 1 0}$ & $\mathbf{0 . 1 0}$ & $\mathbf{0 . 3 4}$ & $\mathbf{0 . 0 5}$ \\
Quality & $\mathbf{0 . 1 5}$ & 0.00 & 0.00 & 0.00 & 0.00 & $\mathbf{0 . 1 9}$ & $\mathbf{0 . 6 1}$ & $\mathbf{0 . 5 9}$ & $\mathbf{0 . 3 1}$ & $\mathbf{0 . 2 4}$ \\
Delivery & $\mathbf{0 . 0 6}$ & 0.00 & 0.00 & 0.00 & 0.00 & $\mathbf{0 . 2 7}$ & $\mathbf{0 . 0 6}$ & $\mathbf{0 . 2 5}$ & $\mathbf{0 . 2 0}$ & $\mathbf{0 . 6 0}$ \\
Innovation & $\mathbf{0 . 5 4}$ & 0.00 & 0.00 & 0.00 & 0.00 & $\mathbf{0 . 2 9}$ & $\mathbf{0 . 2 4}$ & $\mathbf{0 . 0 6}$ & $\mathbf{0 . 1 5}$ & $\mathbf{0 . 1 1}$ \\
NT & 0.00 & $\mathbf{0 . 0 5}$ & $\mathbf{0 . 0 8}$ & $\mathbf{0 . 0 9}$ & $\mathbf{0 . 2 1}$ & 0.00 & 0.00 & 0.00 & 0.00 & 0.00 \\
NP & 0.00 & $\mathbf{0 . 0 8}$ & $\mathbf{0 . 0 7}$ & $\mathbf{0 . 1 1}$ & $\mathbf{0 . 4 0}$ & 0.00 & 0.00 & 0.00 & 0.00 & 0.00 \\
PCS & 0.00 & $\mathbf{0 . 1 9}$ & $\mathbf{0 . 2 3}$ & $\mathbf{0 . 3 4}$ & $\mathbf{0 . 2 6}$ & 0.00 & 0.00 & 0.00 & 0.00 & 0.00 \\
CA & 0.00 & $\mathbf{0 . 2 2}$ & $\mathbf{0 . 1 4}$ & $\mathbf{0 . 2 3}$ & $\mathbf{0 . 0 4}$ & 0.00 & 0.00 & 0.00 & 0.00 & 0.00 \\
O_HR & 0.00 & $\mathbf{0 . 4 7}$ & $\mathbf{0 . 4 7}$ & $\mathbf{0 . 2 3}$ & $\mathbf{0 . 0 9}$ & 0.00 & 0.00 & 0.00 & 0.00 & 0.00 \\
\hline
\end{tabular}

Source: the authors.

TABLE 8: Normalized supermatrix of decision agent 5.

\begin{tabular}{lcccccccccc}
\hline & Ranking & Price & Quality & Delivery & Innovation & NT & NP & PCS & CA & O_HR \\
\hline Ranking & 0.00 & 0.00 & 0.00 & 0.00 & 0.00 & 0.00 & 0.00 & 0.00 & 0.00 & 0.00 \\
Price & $\mathbf{0 . 2 5}$ & 0.00 & 0.00 & 0.00 & 0.00 & $\mathbf{0 . 2 2}$ & $\mathbf{0 . 1 1}$ & $\mathbf{0 . 1 1}$ & $\mathbf{0 . 3 4}$ & $\mathbf{0 . 0 5}$ \\
Quality & $\mathbf{0 . 1 9}$ & 0.00 & 0.00 & 0.00 & 0.00 & $\mathbf{0 . 1 9}$ & $\mathbf{0 . 5 7}$ & $\mathbf{0 . 5 8}$ & $\mathbf{0 . 3 1}$ & $\mathbf{0 . 2 4}$ \\
Delivery & $\mathbf{0 . 0 8}$ & 0.00 & 0.00 & 0.00 & 0.00 & $\mathbf{0 . 2 6}$ & $\mathbf{0 . 0 8}$ & $\mathbf{0 . 2 5}$ & $\mathbf{0 . 2 0}$ & $\mathbf{0 . 6 0}$ \\
Innovation & $\mathbf{0 . 4 8}$ & 0.00 & 0.00 & 0.00 & 0.00 & $\mathbf{0 . 3 2}$ & $\mathbf{0 . 2 4}$ & $\mathbf{0 . 0 6}$ & $\mathbf{0 . 1 5}$ & $\mathbf{0 . 1 1}$ \\
NT & 0.00 & $\mathbf{0 . 1 1}$ & $\mathbf{0 . 0 8}$ & $\mathbf{0 . 1 0}$ & $\mathbf{0 . 2 1}$ & 0.00 & 0.00 & 0.00 & 0.00 & 0.00 \\
NP & 0.00 & $\mathbf{0 . 1 1}$ & $\mathbf{0 . 0 7}$ & $\mathbf{0 . 1 1}$ & $\mathbf{0 . 4 0}$ & 0.00 & 0.00 & 0.00 & 0.00 & 0.00 \\
PCS & 0.00 & $\mathbf{0 . 2 9}$ & $\mathbf{0 . 2 3}$ & $\mathbf{0 . 3 4}$ & $\mathbf{0 . 2 6}$ & 0.00 & 0.00 & 0.00 & 0.00 & 0.00 \\
CA & 0.00 & $\mathbf{0 . 1 7}$ & $\mathbf{0 . 1 4}$ & $\mathbf{0 . 2 3}$ & $\mathbf{0 . 0 4}$ & 0.00 & 0.00 & 0.00 & 0.00 & 0.00 \\
O_HR & 0.00 & $\mathbf{0 . 3 2}$ & $\mathbf{0 . 4 7}$ & $\mathbf{0 . 2 2}$ & $\mathbf{0 . 0 9}$ & 0.00 & 0.00 & 0.00 & 0.00 & 0.00 \\
\hline
\end{tabular}

Source: the authors.

TABLE 9: Weighted supermatrix of the applied example.

\begin{tabular}{lcccccccccc}
\hline & Ranking & Price & Quality & Delivery & Innovation & NT & NP & PCS & CA & O_HR \\
\hline Ranking & 0.00 & 0.00 & 0.00 & 0.00 & 0.00 & 0.00 & 0.00 & 0.00 & 0.00 & 0.00 \\
Price & $\mathbf{0 . 2 9}$ & 0.00 & 0.00 & 0.00 & 0.00 & $\mathbf{0 . 2 6}$ & $\mathbf{0 . 1 0}$ & $\mathbf{0 . 0 9}$ & $\mathbf{0 . 1 8}$ & $\mathbf{0 . 0 6}$ \\
Quality & $\mathbf{0 . 1 6}$ & 0.00 & 0.00 & 0.00 & 0.00 & $\mathbf{0 . 2 1}$ & $\mathbf{0 . 6 1}$ & $\mathbf{0 . 5 8}$ & $\mathbf{0 . 2 3}$ & $\mathbf{0 . 2 5}$ \\
Delivery & $\mathbf{0 . 0 5}$ & 0.00 & 0.00 & 0.00 & 0.00 & $\mathbf{0 . 2 6}$ & $\mathbf{0 . 0 6}$ & $\mathbf{0 . 2 7}$ & $\mathbf{0 . 2 5}$ & $\mathbf{0 . 6 0}$ \\
Innovation & $\mathbf{0 . 4 9}$ & 0.00 & 0.00 & 0.00 & 0.00 & $\mathbf{0 . 2 7}$ & $\mathbf{0 . 2 3}$ & $\mathbf{0 . 0 6}$ & $\mathbf{0 . 3 5}$ & $\mathbf{0 . 0 9}$ \\
NT & 0.00 & $\mathbf{0 . 1 9}$ & $\mathbf{0 . 0 7}$ & $\mathbf{0 . 0 6}$ & $\mathbf{0 . 1 5}$ & 0.00 & 0.00 & 0.00 & 0.00 & 0.00 \\
NP & 0.00 & $\mathbf{0 . 1 7}$ & $\mathbf{0 . 0 8}$ & $\mathbf{0 . 0 9}$ & $\mathbf{0 . 3 9}$ & 0.00 & 0.00 & 0.00 & 0.00 & 0.00 \\
PCS & 0.00 & $\mathbf{0 . 2 6}$ & $\mathbf{0 . 2 4}$ & $\mathbf{0 . 3 1}$ & $\mathbf{0 . 3 2}$ & 0.00 & 0.00 & 0.00 & 0.00 & 0.00 \\
CA & 0.00 & $\mathbf{0 . 1 7}$ & $\mathbf{0 . 1 4}$ & $\mathbf{0 . 2 5}$ & $\mathbf{0 . 0 4}$ & 0.00 & 0.00 & 0.00 & 0.00 & 0.00 \\
O_HR & 0.00 & $\mathbf{0 . 2 1}$ & $\mathbf{0 . 4 8}$ & $\mathbf{0 . 2 8}$ & $\mathbf{0 . 1 0}$ & 0.00 & 0.00 & 0.00 & 0.00 & 0.00 \\
\hline
\end{tabular}

Source: the authors.

Thus, the sum of the preferences was $91 \%$, with the remaining $9 \%$ corresponding to the nonimplementation of the strategic decision regarding "new technologies" due to budget restrictions. It should also be stated that $5 \%$ of the budget was not used.

\section{Conclusions}

Decision-making is the process that leads to the choice of at least one of the different alternatives. In companies, this process is especially important when it involves determining strategies to achieve long-term goals.

Companies are political systems in which strategic decision agents have partially conflicting goals and limited cognitive capacity. Thus, strategic decision-making is more effective when the paradigms of limited rationality and organizational politics are combined.

In turn, CAS are systems made up of components (agents and parts) that interact with each other according to a set of rules. The evolution of the system is the result of interactions 
TABLE 10: Matrix limit corresponding to the decisions of decision agent 1.

\begin{tabular}{lcccccccccc}
\hline & Ranking & Price & Quality & Delivery & Innovation & NT & NP & PCS & CA & O_HR \\
\hline Ranking & 0.00 & 0.00 & 0.00 & 0.00 & 0.00 & 0.00 & 0.00 & 0.00 & 0.00 & 0.00 \\
Price & 0.00 & 0.19 & 0.19 & 0.19 & 0.19 & 0.00 & 0.00 & 0.00 & 0.00 & 0.00 \\
Quality & 0.00 & 0.37 & 0.37 & 0.37 & 0.37 & 0.00 & 0.00 & 0.00 & 0.00 & 0.00 \\
Delivery & 0.00 & 0.29 & 0.29 & 0.29 & 0.29 & 0.00 & 0.00 & 0.00 & 0.00 & 0.00 \\
Innovation & 0.00 & 0.15 & 0.15 & 0.15 & 0.15 & 0.00 & 0.00 & 0.00 & 0.00 & 0.00 \\
NT & $\mathbf{0 . 1 5}$ & 0.00 & 0.00 & 0.00 & 0.00 & 0.15 & 0.15 & 0.15 & 0.15 & 0.15 \\
NP & $\mathbf{0 . 1 7}$ & 0.00 & 0.00 & 0.00 & 0.00 & 0.17 & 0.17 & 0.17 & 0.17 & 0.17 \\
PCS & $\mathbf{0 . 2 5}$ & 0.00 & 0.00 & 0.00 & 0.00 & 0.25 & 0.25 & 0.25 & 0.25 & 0.25 \\
CA & $\mathbf{0 . 1 6}$ & 0.00 & 0.00 & 0.00 & 0.00 & 0.16 & 0.16 & 0.16 & 0.16 & 0.16 \\
O_HR & $\mathbf{0 . 2 8}$ & 0.00 & 0.00 & 0.00 & 0.00 & 0.28 & 0.28 & 0.28 & 0.28 & 0.28 \\
\hline
\end{tabular}

Source: the authors.

TABLE 11: Matrix limit corresponding to the decisions of decision agent 2.

\begin{tabular}{lcccccccccc}
\hline & Ranking & Price & Quality & Delivery & Innovation & NT & NP & PCS & CA & O_HR \\
\hline Ranking & 0.00 & 0.00 & 0.00 & 0.00 & 0.00 & 0.00 & 0.00 & 0.00 & 0.00 & 0.00 \\
Price & 0.00 & 0.07 & 0.07 & 0.07 & 0.07 & 0.00 & 0.00 & 0.00 & 0.00 & 0.00 \\
Quality & 0.00 & 0.35 & 0.35 & 0.35 & 0.35 & 0.00 & 0.00 & 0.00 & 0.00 & 0.00 \\
Delivery & 0.00 & 0.36 & 0.36 & 0.36 & 0.36 & 0.00 & 0.00 & 0.00 & 0.00 & 0.00 \\
Innovation & 0.00 & 0.22 & 0.22 & 0.22 & 0.22 & 0.00 & 0.00 & 0.00 & 0.00 & 0.00 \\
NT & $\mathbf{0 . 0 9}$ & 0.00 & 0.00 & 0.00 & 0.00 & 0.09 & 0.09 & 0.09 & 0.09 & 0.09 \\
NP & $\mathbf{0 . 1 4}$ & 0.00 & 0.00 & 0.00 & 0.00 & 0.14 & 0.14 & 0.14 & 0.14 & 0.14 \\
PCS & $\mathbf{0 . 2 7}$ & 0.00 & 0.00 & 0.00 & 0.00 & 0.27 & 0.27 & 0.27 & 0.27 & 0.27 \\
CA & $\mathbf{0 . 1 5}$ & 0.00 & 0.00 & 0.00 & 0.00 & 0.15 & 0.15 & 0.15 & 0.15 & 0.15 \\
O_HR & $\mathbf{0 . 3 5}$ & 0.00 & 0.00 & 0.00 & 0.00 & 0.35 & 0.35 & 0.35 & 0.35 & 0.35 \\
\hline
\end{tabular}

Source: the authors.

TABLE 12: Matrix limit corresponding to the decisions of decision agent 3.

\begin{tabular}{lcccccccccc}
\hline & Ranking & Price & Quality & Delivery & Innovation & NT & NP & PCS & CA & O_HR \\
\hline Ranking & 0.00 & 0.00 & 0.00 & 0.00 & 0.00 & 0.00 & 0.00 & 0.00 & 0.00 & 0.00 \\
Price & 0.00 & 0.10 & 0.10 & 0.10 & 0.10 & 0.00 & 0.00 & 0.00 & 0.00 & 0.00 \\
Quality & 0.00 & 0.38 & 0.38 & 0.38 & 0.38 & 0.00 & 0.00 & 0.00 & 0.00 & 0.00 \\
Delivery & 0.00 & 0.35 & 0.35 & 0.35 & 0.35 & 0.00 & 0.00 & 0.00 & 0.00 & 0.00 \\
Innovation & 0.00 & 0.16 & 0.16 & 0.16 & 0.16 & 0.00 & 0.00 & 0.00 & 0.00 & 0.00 \\
NT & $\mathbf{0 . 0 9}$ & 0.00 & 0.00 & 0.00 & 0.00 & 0.09 & 0.09 & 0.09 & 0.09 & 0.09 \\
NP & $\mathbf{0 . 1 2}$ & 0.00 & 0.00 & 0.00 & 0.00 & 0.12 & 0.12 & 0.12 & 0.12 & 0.12 \\
PCS & $\mathbf{0 . 2 8}$ & 0.00 & 0.00 & 0.00 & 0.00 & 0.28 & 0.28 & 0.28 & 0.28 & 0.28 \\
CA & $\mathbf{0 . 1 7}$ & 0.00 & 0.00 & 0.00 & 0.00 & 0.17 & 0.17 & 0.17 & 0.17 & 0.17 \\
O_HR & $\mathbf{0 . 3 4}$ & 0.00 & 0.00 & 0.00 & 0.00 & 0.34 & 0.34 & 0.34 & 0.34 & 0.34 \\
\hline
\end{tabular}

Source: the authors.

between agents, where each of them acts in response to the behavior of the others in the system, which ensures them their own dynamic. The agents are responsible for the interaction and the decision process. They are the ones who determine and articulate the direction in which the system will develop. The agents set priorities, from which they make their own choices in a dynamic between conformity and individualism. This phenomenon can be modeled mathematically using three mathematical techniques: (i) the Analytic Hierarchy Process, which defines the ranking between the business dimensions and strategic decisions (according to the wishes and priorities of the agents); (ii) the Analytic Network Process, which defines the interdependence between the dimensions and decision; and (iii) Linear Programing, which optimizes the priorities between the different strategic decisions.

Therefore, there is the conceptual scientific model for ranking a set of strategic decisions. In addition to ranking, the model enables the decision agents to learn regarding issues related to (i) limited rationality, since the technique of Davoodi [31] permits comparisons to be made between the preferences defined by the agents and those that generate the 
TABLE 13: Matrix limit corresponding to the decisions of decision agent 4.

\begin{tabular}{lcccccccccc}
\hline & Ranking & Price & Quality & Delivery & Innovation & NT & NP & PCS & CA & O_HR \\
\hline Ranking & 0.00 & 0.00 & 0.00 & 0.00 & 0.00 & 0.00 & 0.00 & 0.00 & 0.00 & 0.00 \\
Price & 0.00 & 0.14 & 0.14 & 0.14 & 0.14 & 0.00 & 0.00 & 0.00 & 0.00 & 0.00 \\
Quality & 0.00 & 0.39 & 0.39 & 0.39 & 0.39 & 0.00 & 0.00 & 0.00 & 0.00 & 0.00 \\
Delivery & 0.00 & 0.34 & 0.34 & 0.34 & 0.34 & 0.00 & 0.00 & 0.00 & 0.00 & 0.00 \\
Innovation & 0.00 & 0.14 & 0.14 & 0.14 & 0.14 & 0.00 & 0.00 & 0.00 & 0.00 & 0.00 \\
NT & $\mathbf{0 . 1 0}$ & 0.00 & 0.00 & 0.00 & 0.00 & 0.10 & 0.10 & 0.10 & 0.10 & 0.10 \\
NP & $\mathbf{0 . 1 3}$ & 0.00 & 0.00 & 0.00 & 0.00 & 0.13 & 0.13 & 0.13 & 0.13 \\
PCS & $\mathbf{0 . 2 7}$ & 0.00 & 0.00 & 0.00 & 0.00 & 0.27 & 0.27 & 0.27 & 0.27 \\
CA & $\mathbf{0 . 1 6}$ & 0.00 & 0.00 & 0.00 & 0.00 & 0.16 & 0.16 & 0.16 & 0.16 \\
O_HR & $\mathbf{0 . 3 4}$ & 0.00 & 0.00 & 0.00 & 0.00 & 0.34 & 0.34 & 0.34 & 0.34 \\
\hline
\end{tabular}

Source: the authors.

TABLE 14: Matrix limit corresponding to the decisions of decision agent 5.

\begin{tabular}{lcccccccccc}
\hline & Ranking & Price & Quality & Delivery & Innovation & NT & NP & PCS & CA & O_HR \\
\hline Ranking & 0.00 & 0.00 & 0.00 & 0.00 & 0.00 & 0.00 & 0.00 & 0.00 & 0.00 & 0.00 \\
Price & 0.00 & 0.14 & 0.14 & 0.14 & 0.14 & 0.00 & 0.00 & 0.00 & 0.00 & 0.00 \\
Quality & 0.00 & 0.39 & 0.39 & 0.39 & 0.39 & 0.00 & 0.00 & 0.00 & 0.00 & 0.00 \\
Delivery & 0.00 & 0.33 & 0.33 & 0.33 & 0.33 & 0.00 & 0.00 & 0.00 & 0.00 & 0.00 \\
Innovation & 0.00 & 0.15 & 0.15 & 0.15 & 0.15 & 0.00 & 0.00 & 0.00 & 0.00 & 0.00 \\
NT & $\mathbf{0 . 1 1}$ & 0.00 & 0.00 & 0.00 & 0.00 & 0.11 & 0.11 & 0.11 & 0.11 & 0.11 \\
NP & $\mathbf{0 . 1 4}$ & 0.00 & 0.00 & 0.00 & 0.00 & 0.14 & 0.14 & 0.14 & 0.14 & 0.14 \\
PCS & $\mathbf{0 . 2 8}$ & 0.00 & 0.00 & 0.00 & 0.00 & 0.28 & 0.28 & 0.28 & 0.28 & 0.28 \\
CA & $\mathbf{0 . 1 6}$ & 0.00 & 0.00 & 0.00 & 0.00 & 0.16 & 0.16 & 0.16 & 0.16 & 0.16 \\
O_HR & $\mathbf{0 . 3 1}$ & 0.00 & 0.00 & 0.00 & 0.00 & 0.31 & 0.31 & 0.31 & 0.31 & 0.31 \\
\hline
\end{tabular}

Source: the authors.

TABLE 15: Matrix limit corresponding to the harmonization of the decisions of the decision agents.

\begin{tabular}{lcccccccccc}
\hline & Ranking & Price & Quality & Delivery & Innovation & NT & NP & PCS & CA & O_HR \\
\hline Ranking & 0.00 & 0.00 & 0.00 & 0.00 & 0.00 & 0.00 & 0.00 & 0.00 & 0.00 & 0.00 \\
Price & 0.00 & 0.11 & 0.11 & 0.11 & 0.11 & 0.00 & 0.00 & 0.00 & 0.00 & 0.00 \\
Quality & 0.00 & 0.39 & 0.39 & 0.39 & 0.39 & 0.00 & 0.00 & 0.00 & 0.00 & 0.00 \\
Delivery & 0.00 & 0.34 & 0.34 & 0.34 & 0.34 & 0.00 & 0.00 & 0.00 & 0.00 & 0.00 \\
Innovation & 0.00 & 0.16 & 0.16 & 0.16 & 0.16 & 0.00 & 0.00 & 0.00 & 0.00 & 0.00 \\
NT & $\mathbf{0 . 0 9}$ & 0.00 & 0.00 & 0.00 & 0.00 & 0.09 & 0.09 & 0.09 & 0.09 & 0.09 \\
NP & $\mathbf{0 . 1 4}$ & 0.00 & 0.00 & 0.00 & 0.00 & 0.14 & 0.14 & 0.14 & 0.14 & 0.14 \\
PCS & $\mathbf{0 . 2 8}$ & 0.00 & 0.00 & 0.00 & 0.00 & 0.28 & 0.28 & 0.28 & 0.28 & 0.28 \\
CA & $\mathbf{0 . 1 6}$ & 0.00 & 0.00 & 0.00 & 0.00 & 0.16 & 0.16 & 0.16 & 0.16 & 0.16 \\
O_HR & $\mathbf{0 . 3 2}$ & 0.00 & 0.00 & 0.00 & 0.00 & 0.32 & 0.32 & 0.32 & 0.32 & 0.32 \\
\hline
\end{tabular}

Source: the authors.

TABLE 16: Global and individual preferences.

\begin{tabular}{lcccccc}
\hline \multirow{2}{*}{ Strategic decision } & \multicolumn{7}{c}{ Decision agents } \\
& 1 & 2 & 3 & 4 & 5 & All \\
\hline NT & $15 \%$ & $9 \%$ & $9 \%$ & $10 \%$ & $11 \%$ & $9 \%$ \\
NP & $17 \%$ & $14 \%$ & $12 \%$ & $13 \%$ & $14 \%$ & $14 \%$ \\
PCS & $25 \%$ & $27 \%$ & $28 \%$ & $27 \%$ & $28 \%$ & $28 \%$ \\
CA & $16 \%$ & $15 \%$ & $17 \%$ & $16 \%$ & $16 \%$ & $16 \%$ \\
O_HR & $28 \%$ & $35 \%$ & $34 \%$ & $34 \%$ & $31 \%$ & $32 \%$ \\
\hline
\end{tabular}

Source: the authors. consistent matrices, and (ii) organizational policies, as the ANP technique permits individual preferences to be compared with one another and with the harmonized preferences.

The characteristics of the conceptual scientific model make it an indispensable tool for decision processes, as shown by the results of the hypothetical example application.

This study was limited to developing a conceptual scientific model and validating it with a hypothetical example, as it was impossible to obtain real data. Therefore, a suggestion for future studies is to validate it in real problem situations. 


\section{Competing Interests}

The authors declare that they have no competing interests.

\section{References}

[1] D. Wollmann and M. T. A. Steiner, "Complex adaptive systems integrating the decision making process in industrial companies: a scientific conceptual model," Applied Mechanics and Materials, vol. 670-671, pp. 1601-1607, 2014.

[2] D. Wollmann, M. T. A. Steiner, P. J. Steiner Neto, and S. E. Gouvea Da Costa, "Socrates: the CEO-Robot," in Proceedings of the 23rd International Conference on Production Research, Manilla, Filipinas, August 2015.

[3] D. Bin and B. V. J. Castor, "Racionalidade e política no processo decisório: estudo sobre orçamento em uma organização estatal," Revista de Administração Contemporânea, vol. 11, no. 3, pp. 3556, 2007.

[4] R. H. Hall, Organization: Structures, Processes and Outcomes, Pearson Education, New York, NY, USA, 2009.

[5] M. Nooraie, "Factors influencing strategic decision-making processes," International Journal of Academic Research in Business and Social Sciences, vol. 2, no. 7, pp. 405-429, 2012.

[6] I. Gorzen-Mitka and M. Okreglicka, "Improving decision making in complexity environment," in Proceedings of the 21st International Economic Conference (IECS '14), May 2014.

[7] A. H. Ahmed, H. Bwisa, R. Otieno, and K. Karanja, "Strategic decision making: process, models, and theories," Business Management and Strategy, vol. 5, no. 1, pp. 78-104, 2014.

[8] J. D. Hunger and T. L. Wheelen, Essentials of Strategic Management, Pearson, New York, NY, USA, 2013.

[9] H. Mintzberg and J. B. Quinn, The Strategy Process, Prentice Hall, Boston, Mass, USA, 1991.

[10] M. T. Engle, The strategic decision-making process of the board and its impact on decision outcomes [Ph.D. thesis], Weatherhead School of Management Case Western Reserve University, 2013.

[11] M. N. Diga, "Morgan's images of organizations analysis," International Journal of Innovative Research \& Development, vol. 3, no. 13, pp. 201-205, 2014.

[12] G. Barros, "Herbert A. Simon and the concept of rationality: boundaries and procedures," Brazilian Journal of Political Economy, vol. 30, no. 3, 2010.

[13] M. Alam, The strategic decision making process and influence of personality [M.S. thesis], Swedish University, 2013.

[14] C. B. Stephenson, What causes top management teams to make poor strategic decisions? [DBA. thesis], Southern Cross University, NSW, 2012.

[15] M. A. Roberto, "Strategic decision-making processes: beyond the efficiency-consensous trade-off," Paper 14, Management Department Journal Articles, 2004.

[16] C. L. Citroen, Strategic decision-making process: the role of information [Ph.D. thesis], University of Twente, Enschede, The Netherlands, 2009.

[17] P. R. Carlile and C. M. Christensen, "The cycles of theory building in management research," HBS Working Paper 05-057, Harvard Business School, Boston, Mass, USA, 2006.

[18] A. C. Fleury and R. Borgatti Neto, "A self-organized system for production solving: complexity approach," in Proceedings of the 19th International Conference on Production Research, Anais do ICPR, Valparaiso, Chile, 2007.
[19] Y. Bar-Yam, Dynamics of Complex Systems, New England Complex System Institute, Cambridge, Mass, USA, 2003.

[20] R. D. Stacey, Strategic Management and Organizational Dynamics: The Challenge of Complexity, Prentice Hall, Harlow, UK, 2007.

[21] H. Qudrat-ullah, J. M. Spector, and R. I. Davidson, Complex Decision Making: Theory and Practice, NECSI, Cambridge, Mass, USA, 2015.

[22] D. Wollmann, M. T. A. Steiner, G. E. Vieira, and P. A. Steiner, "Details of the analytic hierarchy process technique for the evaluation of health insurance companies," Production, vol. 24, no. 3, pp. 583-593, 2014.

[23] J. Franek and K. Kashi, "A review and critique of MADM methods and applications in business and management," International Journal of the Analytic Hierarchy Process, vol. 6, no. 2, 2014.

[24] S. Sipahi and M. Timor, "The analytic hierarchy process and analytic network process: an overview of applications," Management Decision, vol. 48, no. 5, pp. 775-808, 2010.

[25] A. Ishizaka and A. Labib, "Review of the main developments in the analytic hierarchy process," Expert Systems with Applications, vol. 38, no. 11, pp. 14336-14345, 2011.

[26] N. Subramanian and R. Ramanathan, "A review of applications of Analytic Hierarchy Process in operations management," International Journal of Production Economics, vol. 138, no. 2, pp. 215-241, 2012.

[27] R. Saaty, Panel Discussion. Publishing AHP/ANP Papers, International Symposium on the Analytic Hierarchy Process, Kuala Lumpur, Malaysia, 2013.

[28] T. L. Saaty, "About a hundred years of creativity in decision making," International Journal of the Analytic Hierarchy Process, vol. 7, no. 1, 2015.

[29] T. L. Saaty, Theory and Applications of the Analytic Network Process: Decision Making with Benefits, Opportunities, Costs, and Risks, RWS Publications, Pittsburgh, Pa, USA, 2005.

[30] T. L. Saaty, "The modern science of multicriteria decision making and its practical applications: the AHP/ANP approach," Operations Research, vol. 61, no. 5, pp. 1101-1118, 2013.

[31] A. Davoodi, "On inconsisyency of a pairwise comparison matrix," International Journal Industrial Mathematics, vol. 1, no. 4, pp. 343-350, 2009.

[32] J. Aczél and T. L. Saaty, "Procedures for synthesizing ratio judgements," Journal of Mathematical Psychology, vol. 27, no. 1, pp. 93-102, 1983.

[33] S. Bedessi and S. Lisi, "AHP, ANP, and ANN: technical differences, conceptual connections, hybrid models," in Proceedings of the International Symposium on the Analytic Hierarchy Process (ISAHP '11), Massachusetts, Mass, USA, 2011.

[34] T. Kravchenko and T. Seredenko, "Decision-making with modeling of problem situations using the analytic network hierarchy process ," International Journal of the Analytic Hierarchy Process, vol. 3, no. 1, 2011.

[35] O. Andreichicova and A. Andreichicov, "About some features of AHP-ANP applications," in Proceedings of the 12th International Symposium on the Analytic Hierarchy Process for Multicriteria Decision Making, Kuala Lumpur, Malaysia, 2013.

[36] S. Mostafa, T. Abdelhamid, N. Chileshe, and J. Dumrak, "Decision support model using ANP to align leagile strategies to off-site manufacturing in Australia," International Journal of the Analytic Hierarchy Process, vol. 7, no. 3, 2015. 
[37] L. A. Ocampo and E. E. Clark, "A comprehensive evaluation of sustainable manufacturing programs using analytic network process (Anp)," Multiple Criteria Decision Making, vol. 9, pp. 101-122, 2014.

[38] S. D. Bond, K. A. Carlson, and R. L. Keeney, "Generating objectives: can decision makers articulate what they want?" Management Science, vol. 54, no. 1, pp. 56-70, 2008.

[39] K. A. Richardson, Managing Complex Organizations: Complexity Thinking and the Science and Art of Management, Corporate Finance Review, 2008.

[40] V. Meyer Jr., L. Pascucci, and J. P. Murphy, "Implementing strategies in complex systems: lessons from Brazilian hospitals," Brazilian Administration Review, vol. 9, pp. 19-37, 2012.

[41] E. Morin, On Complexity, Hampton Press, New York, NY, USA, 2008. 


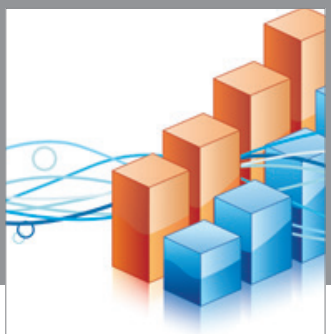

Advances in

Operations Research

vatem alat4

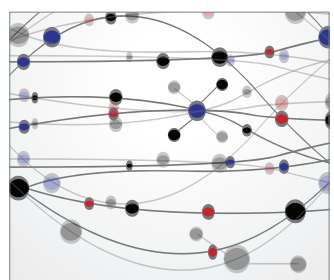

\section{The Scientific} World Journal
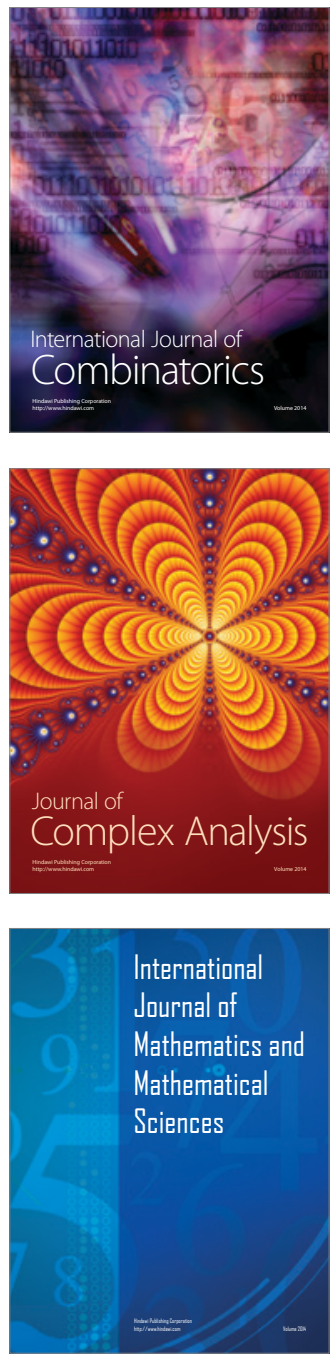
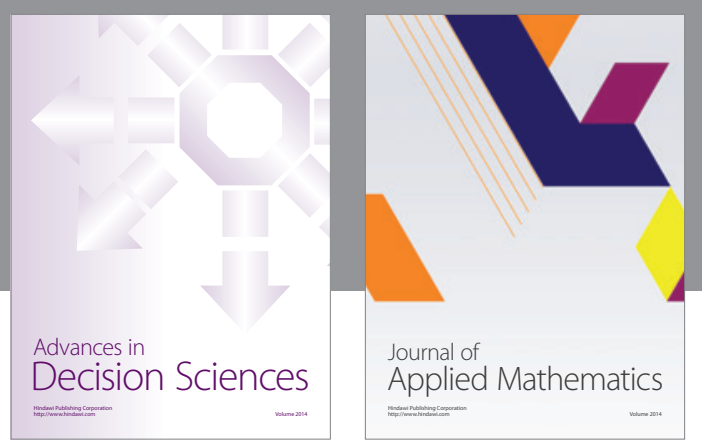

Algebra

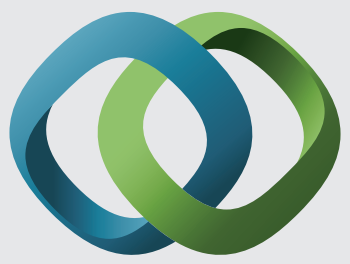

\section{Hindawi}

Submit your manuscripts at

https://www.hindawi.com
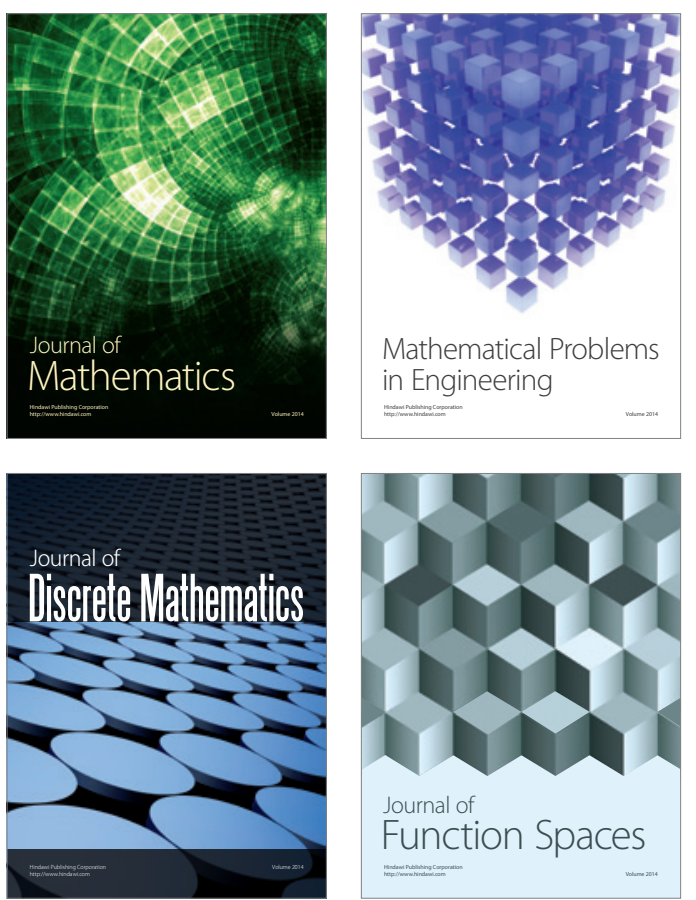

Mathematical Problems in Engineering
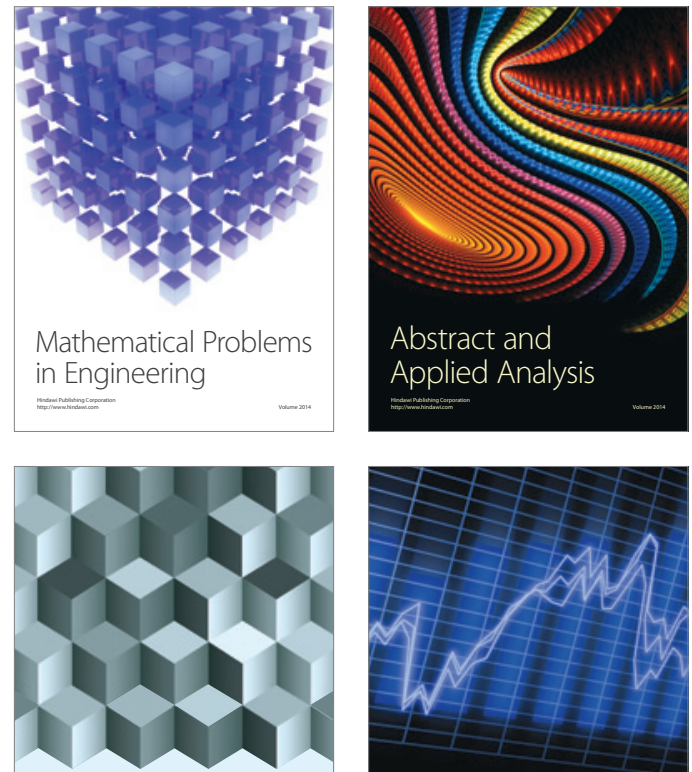

Journal of

Function Spaces

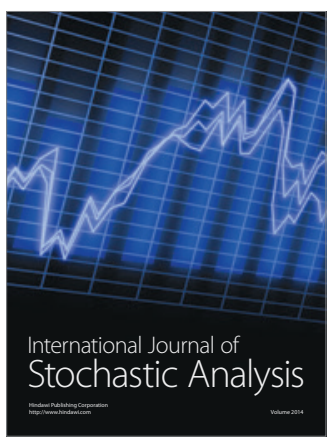

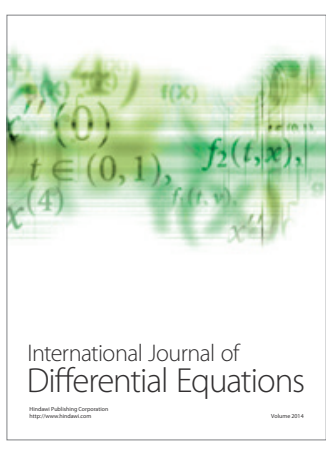
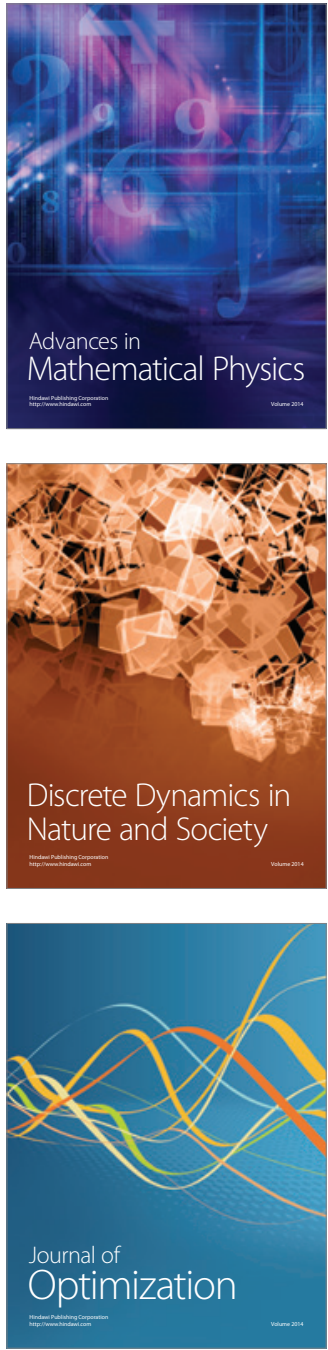